\title{
As Novas Faces do Sindicalismo Rural Brasileiro: A Reforma Agrária e as Tradições Sindicais na Zona da Mata de Pernambuco*
}

\author{
Marcelo Rosa
}

$\mathrm{O}$ sindicalismo rural brasileiro teve nos trabalhadores das lavouras de cana-de-açúcar de Pernambuco um de seus pontos de apoio mais fortes. As greves aí realizadas, no final dos anos 70, reivindicando melhores condições de trabalho, reuniram milhares de trabalhadores e notabilizaram os sindicalistas locais como os mais ativos do país ${ }^{1}$. A ênfase em questões de ordem trabalhista que caracterizava a prática política daqueles sindicatos mudou significativamente em meados dos anos 90, quando a Federação dos Trabalhadores na Agricultura de Pernambuco - FETAPE passou a capitanear um expressivo número de ocupações de terra na região canavieira, chegando, em determinados momentos, a suplantar o Movimento dos Trabalhadores Rurais Sem-Terra - MST, que tradicionalmente detinha o monopólio dessa forma de reivindicação em quase todo o país.

Como essa alteração de perspectiva e de atuação se processou e quais os seus efeitos para a estrutura sindical de uma das principais federações de trabalhadores rurais do país? Este artigo pretende fornecer algumas pistas para responder a tais questões, a partir dos dados de

\footnotetext{
* Este artigo é uma versão ampliada e revisada do relatório produzido para o Consejo Latinoamericano de Ciencias Sociales - CLACSO, no âmbito do concurso Movimentos Sociais e Novos Conflitos na América Latina e no Caribe, no qual fui contemplado com uma bolsa de pesquisa entre janeiro e agosto de 2003.
}

DADOS - Revista de Ciências Sociais, Rio de Janeiro, Vol. 47, n3, 2004, pp. 473 a 503. 
uma pesquisa realizada entre fins de 2002 e meados de 2003, na região da Zona da Mata de Pernambuco. Depois de uma breve apresentação da história da formação do sindicalismo rural em Pernambuco, busco reconstituir o processo que levou a FETAPE a partir para as ocupações de terra, de modo a demonstrar que, mais do que uma estratégia deliberada ou o simples reflexo da conjuntura econômica, essa mudança refletiu um intenso drama social que envolveu gerações distintas de sindicalistas.

\section{ESTADO DAS ARTES: HISTÓRIA DOS SINDICATOS E DAS LUTAS POR TERRA E SALÁRIO NA ZONA DA MATA DE PERNAMBUCO}

A faixa litorânea do Estado de Pernambuco é conhecida geograficamente por Zona da Mata. Nesta região, foram introduzidas as primeiras lavouras de cana-de-açúcar do país, ainda no período colonial. Em torno dessa estrutura produtiva (plantation) se formou uma oligarquia de grandes proprietários com forte poder econômico, os chamados senhores de engenho, os quais exerciam enorme influência sobre o Estado brasileiro, tendo como lastro de sua força centenas de milhares de trabalhadores rurais reunidos sob seu comando.

\section{Lutas por Terra}

Em meados da década de 50, na cidade de Vitória de Santo Antão, na Zona da Mata pernambucana, um grupo de agricultores que cultivavam suas lavouras em terras arrendadas criou uma associação de plantadores em um engenho chamado Galiléia. Identificada pelos proprietários como uma ameaça a seu poder centenário, a pequena associação foi tenazmente combatida e seus associados ameaçados de expulsão da terra ${ }^{2}$.

Aquilo que era um movimento isolado de um grupo de agricultores logo se tornou, pela própria intransigência dos proprietários das terras, um ícone das reivindicações por reforma agrária na região. Associados, pela imprensa local, às Ligas Camponesas que haviam sido formadas pelo Partido Comunista na década de 40, os plantadores da Galiléia acabaram por assumir oficialmente o nome de Liga Camponesa e, auxiliados por grupos políticos de esquerda, rapidamente ampliaram seu movimento por toda a Zona da Mata e diversos outros estados do país. 
Essa vinculação entre reforma agrária e grupos de esquerda (vulgarmente chamados de comunistas) contribuiu para que setores importantes da Igreja Católica se envolvessem em serviços de formação e orientação de lideranças rurais, nos diversos estados do Nordeste, ainda no final dos anos 50. Na Zona da Mata um grande contingente de jovens foi organizado e formado pela Igreja; muitos deles, bem orientados, viriam a fundar sindicatos de trabalhadores rurais em diversas cidades para coibir o avanço das Ligas.

Além da Igreja, ironicamente, o próprio Partido Comunista Brasileiro, que nunca chegou a aceitar por completo as alternativas de "revolução camponesa" propaladas no processo de expansão das Ligas, passou a investir na sindicalização rural como uma das formas de fazer penetrar sua política no campo brasileiro ${ }^{3}$.

Nessas disputas, gradualmente foi sendo gestada uma polarização que opunha as Ligas Camponesas, associadas diretamente com a reforma agrária, aos sindicatos de trabalhadores rurais, que visariam à regulamentação das condições de trabalho nas lavouras. Cabe advertir, no entanto, que as divergências estavam referidas mais à orientação teórica dos grupos do que às suas práticas. O próprio Francisco Julião (1969), que se tornou a principal figura das Ligas, teria saudado a criação dos sindicatos de orientação comunista ou religiosa como uma frente aliada às Ligas, incentivando que os membros destas também se filiassem aos sindicatos de trabalhadores rurais.

Nos primeiros anos da década de 1960, pressões dos partidos políticos, de setores da Igreja Católica e das organizações sindicais que começam a se formar, propiciaram condições favoráveis à regulamentação da atividade sindical no campo em todo o país. A partir de então, o número de sindicatos aumentou significativamente, sobretudo em Pernambuco, onde foi criada, associando católicos e comunistas, a FETAPE. A expansão e consolidação do sindicalismo rural também foram favorecidas pela ascensão de Miguel Arraes à chefia do governo do Estado de Pernambuco, em 1963, com o apoio tanto das Ligas como de importantes parcelas do sindicalismo rural.

Depois da regulamentação do sindicalismo rural e da criação de uma estrutura estatal para apoiar a sua formação, as Ligas perderam seu papel de principais protagonistas das reivindicações camponesas, ocupando um lugar secundário, que lhes dava um diminuto poder de 
barganha política. Esta situação se agravou mais ainda depois do golpe militar de 1964, quando os principais dirigentes das Ligas foram presos, assassinados ou exilados - como ocorreu com o próprio Julião e com o governador Miguel Arraes. No final da década de 60, as Ligas já faziam parte do passado das organizações rurais.

\section{As Lutas por Direitos}

O gradativo fim das Ligas ocorreu concomitantemente com o fortalecimento do sindicalismo rural, que em 1963 criou, sob a chancela do governo federal, a Confederação Nacional dos Trabalhadores na Agricultura - CONTAG - seria o único órgão nacional de representação dos trabalhadores rurais, ao qual estariam filiadas as federações estaduais (como a FETAPE, por exemplo), que, por sua vez, congregariam os sindicatos municipais.

\section{CONTAG $\rightarrow$ Federações Estaduais $\rightarrow$ Sindicatos (STR)}

A CONTAG foi formada com predominância de sindicalistas comunistas, mas teve o apoio também de grupos católicos ligados à Ação Popular. Seu primeiro presidente era de São Paulo, e o vice-presidente era da FETAPE, isto é, de Pernambuco. Nesse processo de sociogênese institucional ou corporativa, as demandas por reforma agrária, apesar de presentes nas principais resoluções da Confederação, como pano de fundo de todos os seus manifestos e publicações, deixaram, gradativamente, de ser uma prioridade prática dos sindicalistas rurais.

Em 1964, logo após o golpe, o governo militar decretou a intervenção na CONTAG e em sindicatos de todo o país, afastando as diretorias eleitas. A intervenção durou até 1967, quando um grupo liderado por um sindicalista pernambucano, cuja formação política se deu nos grupos de evangelização rural, disputou e venceu a chapa dos interventores em uma eleição para a diretoria da confederação. Desde aquele evento, quando se desafiou a ordem imposta pelo governo ditatorial, o sindicalismo rural de Pernambuco tornou-se uma referência para todo o país.

Durante o período do governo militar, os sindicatos da Zona da Mata de Pernambuco desvencilharam-se das influências religiosas e, liderados pela FETAPE, marcaram sua atuação, basicamente, pelas batalhas jurídicas contra os grandes proprietários de terra que desrespei- 
tavam suas obrigações legais para com os empregados. É importante ressaltar que se tratava de um tempo de grande perseguição às lideranças políticas de esquerda no Brasil e que suas ações pela manutenção de direitos trabalhistas se desenrolavam nos tênues limites dos marcos legais postos e impostos pelo governo. Cabe notar também que, nessa mesma época, dado um suntuoso e inaudito investimento estatal, a lavoura de cana-de-açúcar conheceu uma era de grande prosperidade, alavancada pelo Proálcool, programa governamental de incentivo à cultura de cana que subsidiava a produção de álcool combustível visando à substituição do petróleo.

O progressivo aumento dos incentivos estatais à produção de cana não foi, porém, acompanhado de melhorias relativas nas condições de trabalho dos canavieiros. Ao contrário, nesse período, milhares de trabalhadores continuaram a ser mandados embora dos engenhos nos quais moravam e obrigados a viver em condições precárias na periferia das cidades da região $0^{4}$. No final dos anos 70 , mais precisamente em setembro de 1979, a FETAPE, respeitando todas as exigências legais, organizou a maior greve de trabalhadores rurais da história do país, mobilizando milhares de canavieiros na Zona da Mata para lutar por seus direitos trabalhistas.

Os acontecimentos de setembro de 1979 sinalizaram as potencialidades do sindicalismo para mobilizar a enorme massa de trabalhadores da lavoura canavieira, de modo que no ano seguinte uma mobilização ainda maior amealhou os canavieiros para a luta. As manifestações de 1979 e 1980 criaram e consolidaram as greves e as campanhas salariais como os principais instrumentos de pressão do sindicalismo rural de Pernambuco e do Brasil. O sucesso das greves da zona canavieira teve grande repercussão na confederação nacional, que se encarregaria de propagar o caráter exemplar das ações promovidas naquela região pelos quatro cantos do país. As greves tornaram-se o emblema máximo do sindicalismo nacional, constituindo-se em um modelo a ser seguido por todos os estados (Tavares, 1992). Durante a primeira metade dos anos 80 , sindicalistas de todo o país visitaram a Zona da Mata no período em que eram realizadas as campanhas salariais para aprender como se organizavam greves e campanhas salariais.

O relativo sucesso no atendimento das reivindicações por melhores condições de trabalho reafirmou a proeminência da FETAPE no sindicalismo rural brasileiro, consagrando também seus dirigentes. 
A prosperidade da lavoura canavieira e dos sindicatos manteve-se até o final da década de 80. Durante o governo do presidente Fernando Collor de Mello, foram cancelados os subsídios à produção de álcool e açúcar e foi revogada uma série de vantagens concedidas aos produtores de cana, como, por exemplo, a garantia de compra pelo governo federal de todo o excedente produzido. Nesta conjuntura, mais uma vez veio à tona a dependência dos grandes produtores de cana-de-açúcar em relação ao Estado. O corte dos incentivos parece ter incidido diretamente sobre a produção, como mostra a Tabela 1.

Tabela 1

Produção de Cana-de-Açúcar entre 1986

e 1995 em Pernambuco

\begin{tabular}{l|c}
\hline Safra & Milhares de Toneladas \\
\hline $86 / 87$ & $2.576011,6$ \\
$87 / 88$ & $2.011060,0$ \\
$88 / 89$ & $2.049949,8$ \\
$89 / 90$ & $2.188628,9$ \\
$90 / 91$ & $1.867926,0$ \\
$91 / 92$ & $1.832815,7$ \\
$92 / 93$ & $1.725259,8$ \\
$93 / 94$ & $1.205593,8$ \\
$94 / 95$ & $1.695531,8$ \\
\hline
\end{tabular}

Fonte: Sindaçúcar/PE.

O endividamento da maioria dos produtores contribuiu para que, diante da ausência de subsídios, a produção fosse gradualmente reduzida. Esta queda teve reflexos diretos sobre os trabalhadores rurais. Informalmente, os sindicalistas estimam, a partir do número de filiados, que o conjunto dos trabalhadores nas lavouras de cana tenha diminuído de cerca de 240 mil (no tempo das greves dos anos 80) para menos de 100 mil (na segunda metade da década de 1990).

Diante desse quadro de arrefecimento dos investimentos públicos no setor, quatorze das principais usinas de beneficiamento de cana foram fechadas ao longo da década. Muitos dos engenhos onde a cana era plantada ficaram abandonados ou foram entregues aos bancos estatais para o pagamento de dívidas. Estas empresas demitiram seus trabalhadores sem o pagamento de qualquer indenização, alegando não terem fundos para arcar com as despesas contratuais. 
A reação inicial dos sindicatos e da FETAPE foi, assim como nos anos 70 , incentivar os trabalhadores a recorrerem à justiça para receber a indenização. No entanto, a maioria dos proprietários alegou não possuir fundos para saldar suas obrigações patronais e, mesmo com a intervenção da justiça, continuou sem pagar aos trabalhadores o que lhes era de direito.

Nesse contexto, foi revelado um dos paradoxos que estruturaram a notoriedade dos sindicatos rurais na região. Para que um sindicato tivesse sucesso nas suas demandas, ele precisava que elas fossem, de alguma forma, atendidas pelos patrões. Enquanto os incentivos estatais garantiram a boa saúde das oligarquias, os trabalhadores da região conquistaram avanços importantes nas suas condições de trabalho e também na sua remuneração, que era a mais alta de todos os trabalhadores rurais do país. Porém, quando a oligarquia foi atingida no seu principal sustentáculo-o Estado-, os trabalhadores e os próprios sindicatos perderam seu ponto de referência.

\section{O Movimento dos Trabalhadores Rurais Sem-Terra - MST}

O MST - nasceu nos estados do Sul do Brasil, em reação a um reconhecido processo de concentração fundiária. Descendentes de colonos europeus, que gradualmente perderam suas parcas terras, capitanearam, no final dos anos 70, as primeiras fileiras dessa organização que viria a ser uma das mais emblemáticas da luta pela reforma agrária.

Críticos à restrita legitimidade das lutas trabalhistas (que podemos, para efeitos analíticos, nomear como "modelo pernambucano") em uma área dominada pela pequena propriedade, sindicalistas, universitários e também agentes religiosos se aliaram a esses agricultores sem-terra e com eles montaram um acampamento formado por barracas de lona preta em uma fazenda (Fazenda Sarandi) no norte do Estado do Rio Grande do Sul ${ }^{5}$. A princípio, suas manifestações visavam resolver o problema específico de reprodução desse grupo social, para o qual a posse da terra era um elemento central. Com o passar dos anos, as demandas desses colonos foram sendo ampliadas e, em 1984, seus principais líderes fundaram formalmente o MST, cujo objetivo central era lutar pela reforma agrária em todo o país ${ }^{6}$. 
No decorrer dos anos 80, o MST alastrou-se para outros estados brasileiros, e suas manifestações pela desapropriação de latifúndios improdutivos tornaram-se o símbolo por excelência da demanda por reforma agrária no país.

A reforma agrária nas mãos do MST ganhou uma forma própria de ser representada, por meio de um conjunto de símbolos políticos tanto peculiares quanto fortes. $\mathrm{O}$ acampamento nas áreas improdutivas, as barracas de lona preta e a bandeira vermelha tornaram-se a marca registrada do grupo. Com esses símbolos, a presença dos sem-terra fez-se pública na dupla acepção desse termo: tanto a sociedade começou a reconhecer essas pessoas e suas questões, quanto o Estado não pôde mais se esquivar diante daquelas pressões. A gradativa aceitação, por parte dos órgãos estatais, de algumas demandas do MST contribuiu também para a sua consolidação como legítimo representante dos trabalhadores rurais que se consideravam sem-terra. Nesse processo, com os acampamentos proliferando-se por várias regiões do país, a sede do MST foi transferida de Porto Alegre para São Paulo e o movimento passou a contar com uma coordenação nacional, que congregava coordenações estaduais, regionais e municipais.

\section{CONSEQÜÊNCIAS DA CONCORRÊNCIA COM O MST PARA 0 SINDICALISMO RURAL}

O MST aportou em Pernambuco em 1989, ano da primeira eleição para presidente da República depois do golpe de 1964. Reunindo militantes que atuavam nos estados vizinhos, e com o apoio de alguns prefeitos municipais, o movimento organizou a ocupação de uma área pertencente ao governo do Estado na Zona da Mata. O governador de Pernambuco era então Miguel Arraes, uma figura unânime entre os agricultores, que acabara de retornar do exílio. Arraes, no entanto, negou-se veementemente a atender a solicitação dos sem-terra, tornando-se tensas as relações entre eles. A principal justificativa do governo, à época, foi a de que o MST não era um representante legítimo dos trabalhadores rurais de Pernambuco, já que suas lideranças vinham de outros estados. A falta de apoio da FETAPE, sem dúvida a única entidade considerada legítima para representar os trabalhadores da região, foi outro fator decisivo para os problemas de interlocução entre o MST e os representantes do governo de Miguel Arraes. 
Poucos dias depois da ocupação, os militantes e as famílias que haviam montado o acampamento foram violentamente removidos pela polícia. Do acampamento, todos se transferiram para a frente do Palácio do Governo, em Recife. Depois de um longo período de negociações o governo ofereceu uma área de terra na região mais árida do estado, para onde as famílias acabaram por se dirigir. A falta de infra-estrutura, porém, teria levado os sem-terra a abandonar a área ofertada nos meses seguintes.

O MST somente voltaria à região da Zona da Mata no ano de 1992. Desta feita, ao contrário de 1989, seus militantes procuraram manter contato com os sindicatos de trabalhadores rurais. Diante dos primeiros sinais de queda na produção canavieira e da diminuição dos postos de trabalho na região, a proposta do MST de mobilizar trabalhadores rurais para ocupar engenhos que não estivessem produzindo soou interessante para os sindicalistas de duas cidades do sul da Zona da Mata. Em ambos os casos, os presidentes dos sindicatos, que somente conheciam o MST pela televisão, viram nas suas propostas uma possibilidade plausível para mobilizar os trabalhadores rurais da região.

Segundo um desses dirigentes, do Município de Rio Formoso, os militantes do MST o haviam procurado para pedir abrigo nas dependências do seu sindicato enquanto estivessem fazendo seu "trabalho de base" na cidade, ou seja, enquanto visitavam as periferias do pequeno município convidando trabalhadores rurais desempregados para participar de uma ocupação de terra ${ }^{7}$. O trabalho dos militantes do MST atraiu a atenção do presidente e também de um pequeno grupo de jovens que ocupavam posições inferiores na hierarquia do sindicato. O que deveria ser apenas uma ajuda do sindicato ao MST se transformou em trabalho conjunto das duas organizações.

Em abril de 1992, no período de entressafra da cana (quando muitos dos trabalhadores rurais ficam sem emprego), militantes do MST e dirigentes sindicais ocuparam um engenho improdutivo em Rio Formoso. Mesmo não tendo sido bem-sucedida na sua reivindicação da área (os invasores foram despejados pela polícia poucos dias depois), a ocupação sinalizou para sindicalistas e trabalhadores rurais da região uma alternativa aos modos já tradicionais de luta, como as greves e os processos judiciais. 
Neste artigo não poderei tratar dos pontos de vista dos trabalhadores rurais em relação às ocupações, mas creio que o trabalho de Sigaud (2001) forneça pistas suficientes para a compreensão do sentido do engajamento daqueles nessa novidade. Da perspectiva dos sindicalistas, a ocupação parece ter servido como um novo tempero às suas atividades, pois mesmo depois de despejado da primeira ocupação o grupo manteve o acampamento em outras áreas, configurando o que Sigaud chamou de uma "saga" de ocupações, que culminou nas primeiras desapropriações de terra para fins de reforma agrária na região, no ano de 1995.

Após essa primeira ocupação, os militantes do MST e dirigentes sindicais daquela pequena cidade estabeleceram uma espécie de concorrência por áreas que estavam sem produzir. Nesse período, Rio Formoso foi dividida em dois municípios (uma parte da cidade foi emancipada) e um novo sindicato foi formado, sob a liderança de um jovem sindicalista oriundo da diretoria do sindicato antigo. Essa jovem liderança, que havia participado da primeira ocupação, realizada em conjunto com o MST, tornou-se o principal organizador de acampamentos da região e fez da reforma agrária sua principal bandeira ${ }^{8}$.

Entre 1992 e 1995 foram organizados acampamentos em outras cidades da Zona da Mata, alguns por sindicatos e outros pelo MST. Em 1993 a FETAPE, à luz dos eventos do ano anterior, alterou seus estatutos e criou uma secretaria específica para tratar da reforma agrária 9 . Segundo o dirigente que assumiu a coordenação desta Secretaria de Reforma Agrária, porém, sua pasta não significou muitas mudanças na perspectiva da FETAPE em relação às ocupações de terra. A atuação da federação teria se limitado a apoiar ou mediar as negociações nos acampamentos montados pelos sindicatos ou pelo MST. Os dirigentes mais antigos, a quem chamou de históricos, teriam relutado em associar a FETAPE às ocupações de terra. A reticência dos diretores mais antigos e do próprio presidente da FETAPE concentrava-se no fato de que as ocupações, consideradas ilegais e condenadas pelos principais jornais da região, romperiam com a tradição da federação de defender os trabalhadores dentro dos marcos legais.

A dificuldade da FETAPE em assumir a bandeira das ocupações também pode ser atribuída à novidade que estas representavam para a região. Tratava-se de uma experiência inédita que, à época, ainda não havia produzido resultados satisfatórios. 
A posição cautelosa da FETAPE somente começou a se alterar em 1995, ano que parece ter sido decisivo para os propósitos tanto da FETAPE como do MST. Em uma das inúmeras manifestações conjuntas que as duas entidades promoveram, tendo sempre o MST à frente, a sede do Instituto Nacional de Colonização e Reforma Agrária - INCRA - foi ocupada. A demanda principal dos invasores era a nomeação de um diretor permanente para o órgão, que se responsabilizasse pela implementação dos assentamentos de reforma agrária. A manifestação teria sido violentamente reprimida pela polícia, o que levou os dirigentes da FETAPE a retirar os trabalhadores do local, enquanto os membros do MST teriam permanecido. Quando, horas depois de sua retirada, o presidente da República nomeou um novo superintendente para o cargo, os louros da conquista foram revertidos apenas para o MST.

Se até esse episódio o MST precisou se associar à FETAPE para garantir sua legitimidade, depois dessa vitória - ao garantir a nomeação de um novo superintendente para o INCRA - o movimento sentiu-se independente e abandonou o diálogo com a federação. Desde então, o MST vem intensificando as ocupações de terras por toda a Zona da Mata.

Não há como recuperar os dados de todas as ocupações de terra feitas nos primeiros anos da década de 90 . Também não existem registros confiáveis sobre quais seriam as organizações atuantes. Os dados da Comissão Pastoral da Terra - CPT, no entanto, indicam o ano 1995 como um marco na intensificação das ocupações na região.

Tabela 2

Número de Ocupações de Terras na

Zona da Mata de Pernambuco

1993-2000

\begin{tabular}{l|c}
\hline Ano & Número de Ocupações \\
\hline 1993 & 1 \\
1994 & 6 \\
1995 & 21 \\
1996 & 57 \\
1997 & 55 \\
1998 & 76 \\
1999 & 61 \\
2000 & 87 \\
\hline
\end{tabular}

Fonte: Comissão Pastoral da Terra. 
No mesmo ano ocorreu outra eleição na FETAPE. O grupo histórico (dos dirigentes que participaram das primeiras greves) foi mais uma vez vencedor, e a principal alteração na composição da diretoria foi a mudança na Secretaria de Reforma Agrária. O secretário anterior foi substituído por um sindicalista mais jovem, oriundo da Cidade de Vitória de Santo Antão - a mesma das Ligas Camponesas. João Santos era, pelo menos, vinte anos mais novo que os principais dirigentes. Filho de um importante líder sindical dos anos 60 e 70, fora funcionário da FETAPE, entre o final dos anos 80 e o início dos 90, em um pequeno município da região, onde conheceu alguns militantes do MST que organizavam um grande acampamento. Quando seu pai deixou a direção do sindicato dos trabalhadores rurais de Vitória de Santo Antão, depois de várias décadas, foi indicado para substituí-lo. Eleito pela primeira vez em 1993, organizou, logo a seguir, a primeira ocupação de terras conduzida por um sindicato, sem a colaboração direta do MST.

João Santos assumiu seu cargo na diretoria da FETAPE no final de 1995 e, já no início do ano seguinte, a federação passou a assumir publicamente a coordenação das ocupações de terra e acampamentos na região. Da mesma época data a criação da bandeira da FETAPE, para marcar, assim como já fazia a flâmula do MST, a filiação dos agricultores nos seus acampamentos. Sob a coordenação do novo secretário, a federação tratou de incorporar os símbolos até então utilizados somente pelo MST (barracas, bandeiras e ocupações), ampliando igualmente o leque de ações dirigidas à ocupação de prédios públicos, principalmente da sede do INCRA em Recife.

A FETAPE e o MST passam a disputar áreas de acampamentos na região da Zona da Mata. No ano de 1997, a federação realizou o mesmo número de ações que este na Região Metropolitana de Recife. Na Zona da Mata, foi responsável por cerca de 30\% das ocupações, respondendo o MST por $47 \%$ dos $\operatorname{casos}^{10}$.

Sob a batuta de João Santos, a FETAPE retomou seu lugar na vanguarda do sindicalismo rural brasileiro, notabilizada como uma das primeiras federações do país a realizar ocupações de terra ${ }^{11}$. Na esteira desse sucesso, o presidente da FETAPE foi eleito para dirigir a CONTAG, tendo como uma de suas bandeiras a intensificação das ocupações, como forma de pressionar o governo a implementar sua política de reforma agrária. Neste novo contexto, as ocupações de terra 
contribuíram diretamente para reforçar a posição hegemônica dos dirigentes pernambucanos no âmbito nacional.

Na eleição seguinte para a diretoria da FETAPE, João Santos foi mantido no cargo de secretário de Política Agrária, intensificando-se as ocupações de terra na região da Zona da Mata. O sucesso destas, medido pela sua grande repercussão nos jornais, trouxe a FETAPE novamente ao centro da cena política de Pernambuco. No entanto, os feitos exaltados publicamente pela imprensa não correspondiam aos feitos até então capitaneados pelo grupo histórico, ou seja, já não se referiam às campanhas salariais. Mesmo que tivessem apoiado a criação da Secretaria de Reforma Agrária, os sindicalistas do grupo histórico nunca chegaram a participar efetivamente das ocupações ou dos acampamentos promovidos por João Santos.

\section{CONFLITOS INTERNOS}

No ano de 2001, compareci, pela primeira vez, a um evento promovido pela FETAPE em Pernambuco. Tratava-se de um encontro entre os dirigentes estaduais e os delegados sindicais, isto é, os representantes dos sindicatos nos locais de trabalho da região da Zona da Mata.

O evento era dedicado a organizar a pauta de reivindicações que a FETAPE entrega anualmente às entidades patronais todo mês de setembro, desde as greves de 1979. Esses encontros eram voltados, há décadas, para os problemas relativos às condições de trabalho na lavoura da cana.

Nessa ocasião, em especial, boa parte do tempo de debates entre os sindicalistas foi dedicada às estratégias de reivindicação que poderiam ser adotadas para a efetivação das demandas que estavam sendo formuladas. Naquele contexto, chamava a atenção a comparação constante entre as campanhas salariais (greves e direitos) e as lutas por reforma agrária (acampamentos).

Erguendo a primeira bandeira estavam os diretores da FETAPE que estiveram à frente das greves de 1979 e também das bem-sucedidas campanhas salariais dos anos 80 . Suas manifestações lembravam os grandes feitos das décadas anteriores e cobravam dos mais jovens a continuidade daquelas estratégias. A resposta dos mais jovens, sindicalistas que não haviam sido socializados no período das greves, era a condenação dos limites das estratégias passadas e de sua utilização 
no presente. Em seus discursos, propunham que as lutas por salários fossem pensadas no contexto da "crise" das usinas e, portanto, da própria atividade canavieira como centro da vida social da região.

O ápice da disputa entre os dois grupos ocorreu no momento em que o secretário de Reforma Agrária (ligado aos jovens) propôs a realização de uma manifestação pela desapropriação de terras em plena campanha salarial. A reação da maioria dos presentes foi de indignação, pois a proposta rompia com a mais forte tradição do sindicalismo da região, que era a unidade de todos, mesmo os que eram considerados inimigos internos, durante a campanha salarial. Não era possível que uns estivessem em uma frente de luta (a campanha salarial) e outros à frente de manifestações em torno da reforma agrária. Como resumiu um velho sindicalista: "Reforma agrária tem o ano todo, mas campanha salarial somente em setembro." Se os procedimentos tradicionais não fossem tomados como uma obrigação quase natural por todos, a própria magia que animara a vida sindical nos últimos anos poderia ser desfeita.

A campanha salarial representava, portanto, muito mais que um mero instrumento reivindicativo que poderia ser medido por seus resultados práticos. Como alertou Sigaud, o "ciclo de greves", iniciado em 1979, mesmo que não tenha sempre alcançado avanços na regulação do trabalho, era um momento de "afirmação de identidade dos trabalhadores, do fortalecimento de sua unidade em torno de objetivos comuns. Um espaço privilegiado para a consagração do consenso [...]" (Sigaud, 1986:328). Embora as campanhas salariais não apresentassem a mesma eficácia prática de tempos anteriores, sua força residia na manutenção da crença coletiva na sua capacidade de mobilização dos canavieiros, que era nutrida a cada pronunciamento de um sindicalista mais antigo. Os feitos passados forneciam o combustível para o pertencimento a uma entidade que a cada dia via seus quadros encolherem, como podemos ver no depoimento de um dos organizadores da greve de 1979:

“Dirigente: Amanhã [é] uma chapa só, porque não apareceu outra para disputar. Então, a diferença do sindicato que a gente tinha para o que a gente tem hoje é de $95 \%$.

Marcelo: O que mudou?

D: Nós temos $5 \%$ do que a gente tinha antes.

M: Quais são os 5\%? 
D: Porque nós tínhamos, digamos assim, 3.500 associados. 3.500 associados. E agora nós temos, ao todo, 210.

M: Duzentos e dez! Só?

D: Associados em dia com o sindicato. A eleição de amanhã é só 260 pessoas que vai votar. Quem tinha 3.000, 3.000 e poucos associados. Então isso caiu todas as rendas do sindicato. A gente não tem mais funcionários no sindicato. Não temos mais carro no sindicato. [...] Então a gente até dividiu o trabalho.

M: Como é que foi?

D: Porque são três diretores. Eu trabalho segunda e terça, sozinho lá, fazendo tudo. Então o tesoureiro trabalha quarta e quinta, fazendo tudo. Agora, na sexta é que junta nós três pra ver o que fica. Passou-se na semana. Porque o presidente, você sabe, tem que coordenar de qualquer maneira o que acontecer, tem que estar por dentro de tudo para fazer a coordenação."

No entanto, essa fonte de orgulho tinha efeitos diversos para as distintas gerações de dirigentes. Os mais antigos alimentavam-se de algo no qual foram socializados, que realmente lhes tinha sido fundamental, até mesmo para chegarem à destacada posição social que ocupam hoje. Já para os mais jovens, que não viveram o tempo das greves e ingressaram na vida sindical exatamente no momento em que a crise das usinas se intensificava, a memória não servia como alento. Ao contrário, a idealização do passado parecia reafirmar a falta de sentido, no presente, daqueles rituais de congraçamento.

O relativo sucesso alcançado pelas mobilizações por reforma agrária capitaneadas pelo MST mas também, e principalmente, por João Santos, que a cada dia ocupava mais espaço nos meios de comunicação com suas ocupações, serviu de farol aos que não encontravam rumo nas palavras dos mais velhos.

As disputas entre as gerações de sindicalistas que foram socializados em períodos distintos intensificaram-se à medida que o tempo foi passando. Entre 2001 e 2003, acompanhei uma série de eventos públicos e privados envolvendo sindicalistas de todas as idades. Os mais velhos, sempre que tinham oportunidade, reafirmavam a importância das greves e da mesa de negociação como meios adequados para resolver os principais conflitos com o governo e com as entidades patronais. Ao mesmo tempo, criticavam os mais jovens pela falta de temperança, pela forma dita aventureira e individualista como con- 
duziam as mobilizações por reforma agrária. Por outro lado, os sindicalistas envolvidos com as ocupações de terra acusavam seus predecessores de não gostarem de conflitos e de estarem interessados apenas na manutenção de suas posições. Criticavam ainda o grupo histórico por não permitir a ascensão de sindicalistas mais jovens aos postos mais importantes da federação, ou seja, por ter monopolizado as posições de maior prestígio e poder.

De forma sintética, podemos dizer que se foi estabelecendo entre os grupos uma polarização em torno destes elementos:

\begin{tabular}{|l|l|}
\hline Reforma Agrária & Lutas pelos direitos trabalhistas \\
\hline Jovens & Velhos \\
\hline Presente & Passado \\
\hline Ocupação & Negociação \\
\hline Inexperiência & Experiência \\
\hline Irresponsabilidade & Responsabilidade \\
\hline
\end{tabular}

As diferenças entre os históricos e o grupo ligado à Secretaria de Reforma Agrária foram se acentuando a cada reunião da federação. Em determinado momento do mandato iniciado em 1999, as ocupações de terra ou de prédios públicos já não contavam com o apoio irrestrito da direção histórica da FETAPE.

\section{A ÚLTIMA BATALHA}

Em meio a esse processo teve lugar mais uma eleição para renovar a diretoria da FETAPE. O grupo histórico formou sua chapa e a princípio excluiu o nome do secretário de Reforma Agrária.

Desse conflito resultou a formação de duas chapas, uma formada pelo grupo histórico, que colocou no cargo principal um jovem sindicalista sem ligação com as ocupações de terra, e a outra formada por João Santos e pelo secretário de Reforma Agrária que o antecedera. A disputa novamente concentrou-se na polaridade entre reforma agrária e lutas salariais, ou seja, entre uma postura dita combativa, associada com as ocupações, e uma conduta responsável e negociadora que não excluía a luta por reforma agrária, mas pretendia conduzi-la de modo menos conflituoso. 
A chapa histórica foi representada pela cor verde, e a chapa de João Santos, pela cor vermelha. Os significados populares de cada uma das cores - o verde representando esperança e paz, e o vermelho, o combate - indicavam as propostas de cada facção.

Pelas evidências colhidas durante minha pesquisa, menos que dividir a unidade tradicional do sindicalismo rural pernambucano, os conflitos ocorridos nestes últimos anos no âmbito da FETAPE tiveram um caráter renovador.

Para Durkheim (1995:xxxiv), “um grupo não é apenas uma autoridade moral que rege a vida de seus membros, é também uma fonte de vida sui generis. Dele emana um calor que aquece ou reanima os corações, que os abre à simpatia, que faz ruir os egoísmos". Porém, como o mesmo autor adverte, este calor que dota de sentido a vida dos indivíduos na sociedade moderna muda de intensidade com o passar dos anos. A força da história, como processo contínuo de acumulação de experiências, colabora para que os indivíduos se diferenciem a partir de sua socialização.

Naquela eleição, eram visíveis as diferenças entre sindicalistas socializados em contextos distintos. Como vimos, no caso do congresso de delegados que acompanhei, a própria possibilidade de se recorrer a uma memória idealizada de sucesso no tempo das greves despertava sentimentos opostos entre os dirigentes sindicais do grupo histórico e aqueles do grupo ascendente. Para uns, servia de alento em um momento de incerteza; para outros, demonstrava o descompasso entre as necessidades presentes e as realizações passadas.

As contendas entre o grupo histórico e o da reforma agrária animaram de tal forma a vida sindical de Pernambuco que produziram o maior congresso sindical de todos os tempos. Partidários de um grupo e de outro, trabalhadores rurais de todas as partes do estado rumaram para Recife. Vestindo suas camisetas verdes ou vermelhas e entoando animados hinos ao som de pequenas orquestras, todos queriam estar presentes à eleição da nova diretoria da FETAPE.

Como nas eleições anteriores, o grupo histórico sagrou-se vencedor da disputa, porém por uma margem de votos inferior à alcançada nos outros pleitos. Teria a opção pela reforma agrária sido derrotada? 


\section{UM NOVO COMEÇO}

Como descrevi anteriormente, o final do período em que o candidato derrotado no último pleito chefiava a Secretaria de Reforma Agrária foi marcado por uma série de conflitos entre seus simpatizantes e o grupo que aqui chamo de histórico. Um ícone dessas divergências eram justamente as ocupações da sede do INCRA, que se tinham tornado uma rotina nos últimos anos. Consideradas por todos como uma das marcas dos novos tempos da FETAPE (do tempo da reforma agrária), as ocupações deste órgão federal foram, em todas as vezes que acompanhei, planejadas e executadas quase sem interferência da direção da federação, que era comunicada da ação apenas na última hora. A alegada autonomia do grupo da reforma agrária incomodava os dirigentes mais antigos, tanto pelo fato de não participarem da decisão, como também por se tratar de um evento que, em muitos casos, colocava em xeque a própria imagem da FETAPE como uma entidade que sabia negociar. No entanto, o primeiro grande evento organizado pela FETAPE que acompanhei após a vitória do grupo histórico foi exatamente uma ocupação do prédio do INCRA.

O que teria levado o grupo vitorioso a lançar mão, meses depois da eleição, do mesmo artifício que em tempos passados havia sido tão criticado, ou seja, a realizar também uma ocupação do órgão federal? A reposta a essa indagação eu encontrei na própria ocupação, que visitei dias depois.

A ocupação da sede do INCRA em Recife naquela manhã de segunda-feira guardava poucas semelhanças com os eventos que eu acompanhara nos anos anteriores. Se, nas invasões passadas, a presença de uma pequena massa de trabalhadores rurais no pátio do Instituto era sinônimo de tensão e conflito iminente, naquele evento de 2003 o clima era de festa. No pátio do órgão estava armada uma pequena feira composta por barraquinhas que vendiam produtos agrícolas, outras que ofertavam artesanato, e também por balcões das diversas ONGs que prestam assessoria à FETAPE. Havia ainda um carro de som e um trio de zabumba, sanfona e triângulo animando o evento.

Essa disposição em nada lembrava as ocupações que eu havia presenciado anteriormente, fossem as organizadas pela FETAPE, pelo MST, ou por outros grupos. A distribuição das pessoas ligadas à FETAPE nas dependências do INCRA indicava sua organização para além dos 
muros do órgão federal. No lugar das lonas pretas, das foices, pedaços de pau e enxadas, podiam ser vistos murais de cartolina com fotos e frases exemplares escritas com pincel atômico que lembravam os áureos tempos da FETAPE. Em meio a amontoados de mandioca, mulheres debulhando feijão de corda eram saudadas pelos líderes sindicais que circulavam por entre as barracas declarando as benesses alcançadas com o trabalho na terra. O modelo do evento lembrava muito mais as assembléias que antecedem a campanha salarial e os demais encontros que são promovidos pela federação para tratar de assuntos como a previdência social, por exemplo. Ao contrário das outras ocupações, cuja intenção era surpreender os diretores do órgão para obrigá-los a permanecer no local e iniciar negociações extraordinárias, aquela tinha sido previamente agendada com a Superintendência do INCRA, que reservara o dia para negociar com a FETAPE. Enquanto os trabalhadores (que nos eventos anteriores abarrotavam os corredores que davam acesso às salas de reunião) permaneciam do lado de fora, vendendo seus produtos ou engatando um fio de prosa com amigos de outras cidades ao som do forró, do lado de dentro dirigentes e assessores apresentavam sua pauta de reivindicações ao superintendente nomeado há poucos dias.

Além das diferenças simbólicas, chamava a atenção a presença maciça no local de dirigentes, funcionários e assessores responsáveis por outras "frentes de luta", como, por exemplo, educação e previdência social. Pela primeira vez desde que havia iniciado minha pesquisa, encontrei, em uma manifestação identificada explicitamente com a reforma agrária, dirigentes e ex-dirigentes do tempo das grandes greves, participando efetivamente da animação dos trabalhadores e das negociações com o superintendente do INCRA.

A presença dos antigos diretores, do pessoal da animação, das diferentes secretarias e de praticamente todos os funcionários da FETAPE que estavam disponíveis naquele dia definia claramente o sentido que a demanda pela reforma agrária, iniciada nas contendas com o MST, assumia para o sindicalismo rural pernambucano.

Mesmo que o ato estivesse sendo organizado e animado pelos assessores e dirigentes que outrora organizavam as greves e campanhas salariais; mesmo que a disposição estética, assim como nas campanhas, exaltasse os feitos e as formas do passado, a manifestação pela reforma agrária tornara-se, sem dúvida, o leitmotiv da FETAPE naquele 
dia. As pessoas eram as mesmas, mas o simples fato de estarem ocupando uma arena anteriormente interdita àqueles identificados com as greves indicava a importância da mudança.

Para os homens e mulheres que se aglomeraram na sede do INCRA e que, cotidianamente, conformam e reafirmam o espírito do sindicalismo rural em Pernambuco, a participação nas contendas relativas à questão agrária parece ter significado a própria possibilidade de continuidade de suas atividades. Pois foi no espaço conquistado pelas reivindicações recentes por terra que as demandas mais antigas (salários e previdência social, entre outras) puderam ser reorganizadas e expressas com legitimidade.

\section{ARTICULANDO DETERMINAÇÕES}

Como vimos, uma articulação entre diversos determinantes contribuiu para renovar a força e a significação do sindicalismo rural em Pernambuco, dentre os quais se destacam a crise do complexo agroindustrial canavieiro, o conflito geracional e a concorrência entre a FETAPE e o MST.

Creio que seja impossível determinar o peso exato de cada uma dessas variáveis no decorrer do processo de intensificação das ocupações de terra - mesmo porque, ao procurar aferir o peso exato de cada uma delas, estaríamos isolando elementos que só existem em relação com outros. Este procedimento, muito usado na Sociologia, tende a privilegiar uma lógica analítica que opera por meio da desarticulação dos fatos sociais, em detrimento da própria lógica dos processos, ou seja, da lógica da interação ou da síntese (Marx, 1978; Elias, 1997).

Reconhecidas as variáveis mais importantes atuantes nesse processo, resta, agora, compreender como esses elementos relacionados uns com os outros repercutiram sobre o mais tradicional sindicalismo rural do Brasil.

A crise do complexo sucro-alcooleiro pode ser atestada pelo fechamento de algumas das principais usinas de beneficiamento da região e pela redução substantiva do número de trabalhadores rurais empregados nesta atividade social. Cronologicamente, podemos localizá-la na gênese do processo de mudança. No entanto, inexiste qualquer evidência de que esta crise tenha levado diretamente às reivindicações e ocupações de terra. Como me referi anteriormente, a lavoura 
canavieira de Pernambuco atravessou dificuldades em diversos outros momentos nos últimos quatro séculos sem que a reforma agrária fosse vista como uma alternativa. Outro elemento que ajuda a afastar o determinismo econômico como motor da mudança social é a própria história das reivindicações por terra na região. As Ligas Camponesas, por exemplo, reconhecidas como um dos mais importantes movimentos que reivindicaram a posse da terra para os trabalhadores rurais no Brasil, emergiram em um momento de grande prosperidade da indústria canavieira - os anos 60 -, em que os foreiros de diversos engenhos foram ameaçados de expulsão para que suas terras fossem também aproveitadas para o cultivo da cana, ou seja, em um contexto oposto ao que se viu nos anos $90^{12}$.

A conduta inicial dos sindicatos de trabalhadores rurais ante o fechamento de diversas usinas também nos ajuda a desmistificar tal associação. No período de menor produção, entre 1990 e 1994, foram realizadas diversas reuniões para se avaliar as possíveis alternativas à crescente demissão de trabalhadores rurais. Um desses encontros foi o Seminário Regional: Crise e Reestruturação no Complexo SucroAlcooleiro do Nordeste, realizado em 1993, com o apoio da FETAPE, em cujos anais encontramos depoimentos de diversos sindicalistas sobre esse processo, colhidos no momento exato em que ele ocorria. Nenhum deles aludia a uma estratégia calcada apenas na reivindicação da desapropriação das terras, como mostra o depoimento abaixo:

“[...] há uma parte que tem uma experiência da pequena produção, do arrendamento, do foreiro, de coisas assim, mas os seus filhos hoje quase não passaram por estas experiências, assumem o assalariamento. Diante disso, como discutir reforma agrária num contexto desse?" (Assessor sindical no Seminário Regional - Crise e Reestruturação no Complexo Sucro-Alcooleiro do Nordeste. Recife, 1993).

Diante da insolvência dos empresários, a avaliação mais comum entre sindicalistas e seus assessores apontava para a necessidade da manutenção das lutas por direitos trabalhistas que estavam sendo constantemente desrespeitados pelos patrões. A crise foi interpretada, a princípio, como uma estratégia patronal para aumentar seus lucros. Muitos sindicatos voltaram-se para a defesa da manutenção dos empregos na Justiça do Trabalho, exigindo que os empregadores cumprissem suas obrigações legais, principalmente pagando as multas pela demissão injustificada de trabalhadores. 
Outro ponto que também chama a atenção é o fato de a intensificação das ocupações de terra, principalmente por parte dos sindicatos, ter ocorrido a partir de 1995, principalmente em 1996, momento em que a produção de cana voltava a crescer consideravelmente, o que desautoriza qualquer associação direta entre crise na produção e mudanças nas condutas dos sindicatos.

Pelo que vimos até o momento, portanto, a "crise" da atividade canavieira teria influenciado somente de forma indireta a mobilização do sindicalismo pernambucano para realizar ocupações de terras. Sua maior contribuição parece ter sido disponibilizar uma grande massa de trabalhadores e, mais ainda, justificar ideologicamente a atuação dos sindicatos nesta outra seara. Contudo, em todas as entrevistas que realizei com sindicalistas e assessores a crise sempre foi apresentada como justificativa oficial para a reivindicação da reforma agrária. Abaixo apresento alguns trechos de entrevistas em que este tipo de justificativa se destaca:

“Marcelo: Eu queria saber, inicialmente, como essa demanda da reforma agrária chegou aqui?

Assessor: É uma história antiga [...] Já vem da fase anterior a Julião, mas intensifica-se com ele no Engenho Galiléia, em Vitória. Também se liga com a história dos sindicatos... no processo de consolidação dos sindicatos na Zona da Mata, e passa a ter uma ênfase mais forte para o final da década de 80 e durante todo os 90 , quando coincidem algumas mudanças dentro de Pernambuco, no país e fora do país. A mais sensível e a mais evidente delas é o início da deterioração da economia sucro-alcooleira. A mudança no regime de subsídios que sustentou essa economia durante muitos anos. (Assessor jurídico da FETAPE, setembro de 2001).

$[\ldots]$

Presidente: Tivemos 240 mil trabalhadores aqui, hoje nós temos na faixa de 100 mil. A maior parte são contratados temporários. Só alguns sindicatos que começou a entender que tem que mudar. (Presidente da FETAPE, setembro de 2001)

[...]

Marcelo: Quando surgiram os acampamentos aqui na região?

Dirigente: No ano de 1993, 1994, mais ou menos. Nessa época surgiu esse primeiro acampamento, mas surgiu da necessidade dos trabalhadores, por conta das demissões em massa das empresas, do desempre- 
go desenfreado e da fome que estava batendo solta. (Ex-presidente de sindicato na parte sul da Zona da Mata, maio de 2002)

[...]

Dirigente: Essa crise no setor desestabilizou alguns sindicatos [...] Aqueles sindicatos que as empresas ainda se mantiveram bem, viveram bem, eles estão ainda com o potencial, os trabalhadores trabalhando [...] Mas aqui onde tem problema, naquele município que a empresa faliu, está pré-falida, a situação é mais complicada. É tal que você... Há uns dez anos para trás, você falar de reforma agrária na zona canavieira era difícil, era problemático você convencer um trabalhador para ele sair do salário, para ir pegar um pedaço de terra. Você contava nos dedos alguns que queriam. Agora, de uns cinco ou seis anos pra cá ficou mais fácil você fazer um trabalho de conscientização da terra. Em determinado momento o pessoal ficou sem opção. Ele procura e não encontra.

Marcelo: Não tem o que fazer?

Dirigente: Não tem o que fazer, vai brigar pela terra (ex-presidente da FETAPE, outubro de 2001)".

Por meio das entrevistas e da análise dos materiais de arquivo foi possível notar que a justificação das ocupações pela crise é uma elaboração realizada depois do início do processo, a qual encontra ressonância na atividade sindical, entre outras razões, porque é coerente com o tipo de intermediação entre capital e trabalho realizado pelos sindicatos. No entanto, como vimos anteriormente, não foram os dirigentes históricos que organizaram as primeiras ocupações de terras feitas pelos sindicatos.

A existência de uma crise estabeleceu as condições para que jovens sindicalistas pudessem contrapor-se à ordem hierárquica vigente desde as greves de 1979. Os problemas práticos passaram a ser enfrentados nos primeiros anos da década de 90, quando a tradicional prática de "botar na justiça" não surtiu os efeitos que dela esperavam os sindicalistas mais experientes. Essas investidas frustradas prenunciaram muito mais do que o esgotamento de uma "frente de luta". Pela primeira vez em muitos anos foi possível aventar a possibilidade de se estar encerrando o ciclo político da geração das greves.

No entanto, foi por obra de um dos velhos sindicalistas (o dirigente de Rio Formoso) que os sindicatos se aproximaram do MST. Ao abrigar nas dependências da entidade os jovens militantes do MST que vi- 
nham de outros estados, aquele dirigente sindical proporcionou um espaço de socialização e, por conseguinte, de aprendizado de novas formas de reivindicação para um grupo de jovens sindicalistas que rapidamente seria seduzido pela bandeira das ocupações.

Em contextos favoráveis, como o do sindicato de Rio Formoso, que se dividiu em dois, foi possível manter a relação intergeracional sem que o conflito pelo poder se estruturasse de fato, pois havia lugar para todos. O mesmo, porém, não ocorreu na FETAPE, cuja diretoria não podia fortalecer novos integrantes sem prejudicar os dirigentes mais velhos. Como aponta Sigaud (2001), foram esses jovens sindicalistas, radicados posteriormente no recém-constituído sindicato da Cidade de Tamandaré (PE), que passaram a disputar áreas improdutivas com o MST.

Como assinalei acima, o congresso de delegados sindicais a que compareci foi marcado pela cisão entre os diretores mais antigos, que defendiam a valorização da memória das grandes greves, e os diretores mais jovens, que a todo momento lembravam que "a luta agora é outra". As dicotomias entre passado e futuro, entre lutas por terra versus lutas por direitos, também se ancoravam na alegada perda de eficácia das greves como estratégia de reivindicação durante a crise dos anos 90. Segundo pesquisadores que acompanharam o mesmo evento em anos anteriores, os atos de contar a história (encenados pelos antigos sindicalistas) não ocupavam, então, tanto espaço como quando do evento a que assisti ${ }^{13}$. Essa informação reforça a hipótese de que a ênfase nas dicotomias entre passado e presente, tanto de um lado como do outro, serviu para anunciar um embate que se estruturava cotidianamente nos corredores da FETAPE. Naquele momento específico, a concorrência com o MST, que incitara a criação e fortalecimento da Secretaria de Reforma Agrária, já não era o carro-chefe que contribuía para a intensificação cada vez maior das ocupações de terra pela FETAPE. A concorrência com o MST havia penetrado no seio da própria federação e se radicado entre os jovens sindicalistas, que ao organizarem ocupações de terras se empenhavam em reunir novos simpatizantes, de modo a aumentar seu poder dentro da organização sindical.

Como adverte Norbert Elias (1997:221-222), "seria igualmente simplista incriminar as gerações mais velhas, detentoras das posições mais elevadas de carreira e do establishment, por restringir o acesso de 
pessoas mais jovens às desejadas oportunidades de vida em longos períodos $[\ldots] "$. . Os intensos dramas sociais que vivenciei na região mais tradicional do sindicalismo rural brasileiro não foram fruto de uma estratégia elaborada pelos sindicalistas mais antigos.

Os diretores do tempo das greves haviam construído uma carreira na qual sua história de vida se confundia com a história do sindicalismo rural. Todos eles entraram para os sindicatos municipais e, depois, para a FETAPE ainda muito jovens e dedicaram suas vidas ao combate contra uma das mais poderosas oligarquias do país. Como recompensa, receberam remunerações acima da média para um trabalhador rural e, mais do que isto, a admiração e gratidão de milhares de trabalhadores que passaram a desfrutar de direitos historicamente negados. Em uma sociedade na qual o reconhecimento individual é dado pela interpendência entre os sujeitos sociais, deixar uma posição social que provia a vida de pessoas comuns de um sentido especial não foi tarefa simples. Para os diretores que conheci, perder seu lugar na FETAPE era perder seu lugar no mundo. Era destituir-se do próprio sentido de suas vidas.

Não foi outra a sensação que me transmitiu o jovem João Santos quando soube que seu nome não seria incluído na chapa favorita e percebeu que sua ascensão social na FETAPE estava bloqueada pelos mais velhos. A partir do contato com o MST, porém, ele aos poucos foi construindo, dentro e fora do sindicalismo, uma reputação cujo símbolo maior eram as ocupações de terra. Foi participando das marchas e ocupações que ele ganhou as páginas dos principais jornais do país como um dos primeiros sindicalistas a adotar as ocupações como instrumento para a realização da reforma agrária. João Santos, assim como seus companheiros do tempo das greves, tornou-se um indivíduo especial, com um certo poder de decisão sobre a vida de muitos trabalhadores rurais de sua região.

Levando em consideração o caráter coletivo desses dramas individuais, percebemos o quão importante foram as experiências de contato e concorrência do sindicalismo rural pernambucano com o MST. Produtos de contextos políticos distintos, estes dois tipos de organização compartilharam, na região canavieira de Pernambuco, um importante processo de mudança social. Se, no começo, o MST parecia estar mais adaptado à crise, logo os sindicatos tratariam de dar sua respos- 
ta na mesma moeda, e com a vantagem de estarem organizados há muito mais tempo.

Neste artigo, tratei apenas dos efeitos que este movimento constante de ação e reação teve para o sindicalismo, mas o contrário também poderia ter sido feito, pois em nenhuma outra parte do Brasil o MST encontrou uma concorrência tão forte. A partir do ponto de vista dos próprios sujeitos que vivenciaram os processos sociais, e não de uma perspectiva teórica exterior a eles, do desvelamento de seus dilemas e contradições, foi possível compreender o sentido renovador dessa experiência para a atividade sindical na região. Renovador não como uma oposição entre velhas e novas formas de ação, mas como um modo de reanimar o mundo social dos sindicalistas.

O espelho do MST estabeleceu a possibilidade de criação de uma nova oportunidade para os jovens que se especializaram em uma frente de luta que não era prestigiada pelos dirigentes mais antigos, permitindo que viessem a ser reconhecidos pela condução das manifestações por reforma agrária. Para o grupo histórico, a concorrência com o MST e com a geração mais nova permitiu a incorporação de novos métodos de reivindicação e, mais do que isto, talvez tenha representado a continuidade do reconhecimento público da importância do grupo em uma época de intensa desregulamentação de direitos trabalhistas antes considerados fundamentais ${ }^{14}$.

\section{CONCLUSÃO}

Em um momento em que o Movimento dos Trabalhadores Rurais Sem-Terra se impõe à sociedade brasileira como o principal sujeito das reivindicações de cunho agrário, torna-se premente uma análise do impacto dessa organização no sindicalismo rural que outrora ocupou com destaque este papel. Este artigo procurou pensar essa relação a partir das suas determinações em diferentes escalas, privilegiando a compreensão do ponto vista dos envolvidos na mudança, ou seja, dos próprios sindicalistas.

Além de negar a naturalidade das dicotomias sociológicas que costumam polarizar lutas por terra e lutas por salários, os fenômenos observados na Zona da Mata de Pernambuco nos últimos anos nos mostram a importância de ter em conta que essas instituições são formadas por indivíduos, cujos distintos interesses conformam os sentidos 
das ações que promovem como dirigentes sindicais. O acompanhamento sistemático dos eventos promovidos pela FETAPE permitiu-me perceber que a adesão desse tradicional pólo de defesa dos trabalhadores rurais ao modelo forjado pelo MST não refletiu apenas as mudanças estruturais da sociedade brasileira, tendo sido guiada também pelas estruturas internas da formação sindical e por suas condições históricas de reprodução.

Assim, vimos que aquilo que se manifesta exteriormente como uma mudança no sindicalismo representou, mais objetivamente, uma alteração na distribuição de poder dentro da federação de trabalhadores rurais mais importante do país. A relação entre processos internos (conflitos geracionais) e externos (crise econômica e emergência de novas organizações) possibilitou a unificação de um grupo em torno da demanda por reforma agrária e reforçou a associação entre os sindicalistas mais velhos e as lutas salariais. O conflito entre novas e velhas formas de organização e de luta política, que em um primeiro momento poderia ser visto como prejudicial à unidade da federação, contribuiu para que o sindicalismo rural voltasse a ocupar um papel destacado na representação dos trabalhadores rurais da região, ao incorporar seletivamente formas e pautas de reivindicação forjadas por outros grupos sociais. Por fim, vimos que a FETAPE não se transformou em uma organização semelhante ao MST; ao contrário, a pesquisa mostrou que os sujeitos e as formas tradicionais de se fazer política no campo podem incorporar novas demandas sem perder sua identidade histórica, ou seja, sem deixarem de ser um sindicato, no sentido clássico do termo ${ }^{15}$.

(Recebido para publicação em março de 2004) (Versão definitiva em junho de 2004) 


\section{NOTAS}

1. Isto não significa que o grupo não tenha sido alvo de críticas de setores que gostariam de ver incluídas no programa de lutas desses trabalhadores reivindicações ativas por reforma agrária.

2. Segundo Callado (1960:34), a associação havia sido fundada porque "o foro alto fez com que vários foreiros da Galiléia começassem a atrasar, a dever dinheiro, a afogar tudo em Pitu. [...] Eles precisavam organizar uma sociedade, criar um fundo, para amparar os que adoecem e pagar as dívidas dos atrasados".

3. Agradeço a um dos pareceristas anônimos de Dados pela advertência de que a proposta de sindicalização do Partido Comunista Brasileiro - PCB é anterior à criação das Ligas Camponesas. Como não havia base legal que permitisse a sindicalização, porém, o partido voltou-se para a criação de associações que, em alguns casos, foram transformadas em sindicatos quando a legislação o permitiu. É importante lembrar, ainda, que nessa época já havia, principalmente nos estados do Sul do Brasil, uma federação de trabalhadores e lavradores, a União dos Lavradores e Trabalhadores Agrícolas do Brasil - ULTAB, criada sob a influência direta do Partido Comunista Brasileiro.

4. Para uma análise mais detalhada dos processos de expropriação e precarização do trabalho nas lavouras canavieiras ver Palmeira (1979) e Sigaud (1979).

5. No caso específico desta ocupação, sua base era formada por famílias inteiras de colonos que haviam sido expulsas das áreas indígenas do norte do Rio Grande do Sul. Para maiores informações sobre o caso ver Gehlen (1983).

6. De fato, os acampamentos não eram formados apenas por descendentes de imigrantes europeus, mas foram os colonos, como eram chamados, que tomaram as rédeas do movimento e formularam suas principais demandas. Não por acaso este ficou conhecido como "movimento dos colonos sem terras". Para uma análise mais detalhada do evento ver o trabalho de Gehlen (1983).

7. OSindicato dos Trabalhadores Rurais de Rio Formoso foi um dos mais ativos pólos das lutas salariais e por direitos trabalhistas nas décadas anteriores. Seu principal dirigente ocupou, durante o final da década de 80, importantes cargos na diretoria da federação estadual.

8. O nome deste dirigente foi o que por mais vezes apareceu nas solicitações de desapropriação de terras feitas à Superintendência do Instituto Nacional de Colonização e Reforma Agrária - INCRA em Recife desde 1980.

9. A organização de secretarias de acordo com as chamadas "frentes de luta" está diretamente relacionada à presença de sindicalistas ligados à Central Única dos Trabalhadores - CUT na CONTAG e na FETAPE. No entanto, o fato de ter sido criada uma Secretaria de "Reforma Agrária", e não de outra luta, indica que o problema estava posto (a meu ver pela chegada do MST) para os sindicalistas pernambucanos. Se analisarmos as secretarias criadas na FETAPE nos últimos anos, poderemos constatar que sua emergência está ligada à imposição social de novos problemas ou, no linguajar sindical, de novas lutas, como foi o caso, por exemplo, das Secretarias de Mulheres e de Jovens, criadas mais recentemente.

10. Segundo dados do INCRA para 1997. 
11. Existem informações, não confirmadas pelos dados oficiais, de que as federações de São Paulo e Minas Gerais também haviam realizado ocupações de terra.

12. Os próprios sindicatos, nas campanhas salariais das décadas anteriores, nunca deixaram de ter como ponto de pauta a destinação de uma área dos engenhos para o plantio de uma lavoura de subsistência dos canavieiros (a chamada Lei do Sítio). A realização de ocupações, no entanto, não é mencionada nos documentos sindicais da época.

13. Agradeço principalmente os comentários de Lygia Sigaud sobre os eventos que presenciara em anos anteriores.

14. Sobre algumas das conseqüências recentes da desregulamentação do trabalho no Brasil, ver Cardoso (2003).

15. Contribui para esta constatação o fato de que, após ser derrotado na eleição da FETAPE, João Santos tenha criado uma nova organização (um movimento, nas suas palavras), nos moldes do MST, a Organização de Luta no Campo - OLC, dedicada exclusivamente a organizar ocupações de terra para exigir a desapropriação de áreas para fins de reforma agrária.

\section{REFERÊNCIAS BIBLIOGRÁFICAS}

CALLADO, Antonio. (1960), Os Industriais da Seca e os Galileos de Pernambuco. Rio de Janeiro, Civilização Brasileira.

CARDOSO, A. (2003), A Década Neoliberal e a Crise dos Sindicatos no Brasil. São Paulo, Boitempo.

DURKHEIM, E. (1995), Da Divisão do Trabalho Social. São Paulo, Martins Fontes.

ELIAS, N. (1997), Os Alemães: A Luta pelo Poder e a Evolução do Habitus nos Séculos XIX e $X X$. Rio de Janeiro, Jorge Zahar Editor.

GEHLEN, I. (1983), Uma Estratégia Camponesa de Conquista da Terra e o Estado: O Caso da Fazenda Sarandi. Dissertação de Mestrado em Sociologia, UFRGS.

JULIÃO, F. (ed.). (1969), “Ligas Camponesas, outubro 1962-abril 1964”. Cuadernos CIDOC, $\mathrm{n}$ ㅇ 27, Cuernavaca, México.

MARX, K. (1978) [1857], “Introdução à Crítica da Economia Política”, in J. A. Giannotti (org.), Marx. São Paulo, Abril Cultural (Coleção Os Pensadores).

PALMEIRA, M. (1979), “Desmobilização e Conflito: Relações entre Trabalhadores e Patrões na Agroindústria Pernambucana". Revista de Cultura e Política, nํㅡ1, vol. 1, pp. 41-55.

SIGAUD, L. (1979), Os Clandestinos e os Direitos. São Paulo, Duas Cidades. . (1986), “A Luta de Classe em Dois Atos: Notas sobre um Ciclo de Greves Camponesas". Dados, vol. 29, nº 3, pp. 319-343. 
(2001), “Histories de Campements". Cahiers du Brésil Contemporain, nos. 43/44, pp. 31-70.

TAVARES, R. (1992), CONTAG, da Ditadura à Transição; Memória Social e Construção Política do "Campesinato. Dissertação de Mestrado, IUPERJ.

\section{ABSTRACT}

The New Faces of the Rural Labour Movement: Agrarian Reform and Union Tradition in the Zona da Mata in Pernambuco

This article seeks to understand the fact that Pernambucan unionists have joined occupations of land, as well as the consequences of this new practice for the labour movement in other states where the Landless Workers' Movement (MST) is a monopoly force. Based on a systematic study of events organized by FETAPE (the rural labour federation of Pernambuco), it emerges that this traditional labour organization started to follow the model forged by the MST guided in large part by its internal union education structures, historic conditions of reproduction and especially by generational conflict between its members.

Key words: agrarian reform; Landless Worker's Movement; Zona da Mata 


\section{RÉSUMÉ}

Les Nouveaux Visages du Syndicalisme Rural Brésilien: La Réforme Agraire et les Traditions Syndicales à la Zona da Mata au Pernambouc

Dans cet article, on cherche à comprendre le sens de l'engagement de certains syndicalistes du Pernambouc dans les actions d'occupation des terres ainsi que les conséquences de cette nouvelle pratique observée dans d'autres États brésiliens sous l'égide du MST (Mouvement des Sans-Terre) pour le syndicalisme rural vu comme le plus dynamique du pays. À l'aide d'une analyse centrée surtout sur le suivi systématique des événements organisés par la FETAPE (Fédération des travailleurs de l'agriculture à Pernambouc), on a pu percevoir que l'adhésion de ce traditionnel pôle de défense des travailleurs ruraux au modèle fabriqué par le MST a été dictée, en grande partie, par les structures internes elles-mêmes de la formation syndicale, par leurs conditions historiques de reproduction et surtout par un conflit de générations entre ses membres.

Mots-clé: réforme agraire; Mouvement des Sans-Terre; Zona da Mata 